\title{
Influencia de la aplicación de vinaza en la estructura de comunidades bacterianas en un Entic dystropept y un Fluventic haplustoll del Valle del Cauca, Colombia
}

\author{
Influence of the application of vinasse in the structure \\ of bacterial communities on an Entic dystropept and a \\ Fluventic haplustoll of the Valle del Cauca, Colombia
}

\author{
Influência da aplicação de vinhaça sobre a estrutura das \\ comunidades bacterianas em um Entic dystropept e um Fluventic \\ haplustoll do Valle del Cauca, Colombia
}

\begin{abstract}
Sandra Patricia Montenegro Gómez ${ }^{1}$, Juan Carlos Menjivar Flóres² \& Donald Riascos³
'Licenciada en Biologia y Quimica, Especialista en manejo y conservación de suelos y aguas, Magister en ciencias agrarias, énfasis suelos, Doctora en Ciencias área de concentración microbiología Agrícola. ${ }^{2}$ Ingeniero Agrónomo, Magister en Suelos y Aguas, Doctor en Ciencia del Suelo.

${ }^{3}$ Agrónomo del Trópico Húmedo, Magister en ciencias agrarias, énfasis fitopatología.

1, 2 Facultad de Ciencias Agropecuarias. Universidad Nacional de Colombia. Sede Palmira.

${ }^{3}$ Programa de Agronomía. Universidad del Pacífico. Colombia.
\end{abstract}

1'spmontenegrog@palmira.unal.edu.co, 2jcmenjivar@unal.edu.co, ${ }^{3} \mathrm{~d}$ hriascoso@gmail.com

\section{Resumen}

Se evaluó el efecto de aplicación de vinaza y potasio sobre la estructura de comunidades bacterianas de maíz dulce (Zea mays) en un Entic dystropept y en un Fluventic haplustoll del Valle de Cauca, Colombia. Se siguió un diseño completamente al azar con cuatro tratamientos y cinco repeticiones: $\mathrm{T} 1$ (100\% requerimiento de $\mathrm{K}^{+}$con $\mathrm{KCl}), \mathrm{T} 2\left(100 \%\right.$ requerimiento de $\mathrm{K}^{+}$con vinaza), T3 $\left(50 \%\right.$ requerimiento de $\mathrm{K}^{+}$con $\mathrm{KCl}+50 \%$ con vinaza) y $\mathrm{T} 4\left(25 \%\right.$ requerimiento de $\mathrm{K}^{+}$con $\mathrm{KCl}$ $+75 \%$ con vinaza). Se estableció la relación entre estructuras de comunidades microbianas y aplicación de vinaza por el método PCR-DGGE de amplicones del gen rRNA 16S. El T1 y T2 del Entic dystropept presentó mayor número de amplicones y el análisis clúster de distancia euclidiana indicó que existe similaridad de comunidades bacterianas en estos tratamientos donde tanto la vinaza como $\mathrm{KCl}$ fueron aplicados para suplir el $100 \%$ de fuente de potasio

Palabras clave: Inceptisol; Mollisol; PCR-DGGE, Vinaza, comunidades microbianas

\section{Abstract}

The effect of vinasse application on the structure of bacterial communities in a Entic Dystropept and a Fluventic haplustoll Cauca Valley, Colombia was evaluated. to meet the requirements of $\mathrm{K}^{+} \mathrm{crop}$ of sweet corn (Zea mays L.). Experimental design was completely randomized with four treatments and five replications: $\mathrm{T} 1$ (100\% requirement of $\mathrm{K}$ $+\mathrm{KCl})$, T2 (100\% requirement of $\mathrm{K}+$ with vinasse ), T3 $(50 \%$ requirement of $\mathrm{K}+\mathrm{KCl}+50 \%$ with vinasse) and $44(25 \%$ requirement of $\mathrm{K}+\mathrm{KCl}+75 \%$ with vinasse). The relationship between microbial 
community structure and application of vinasse by PCR-DGGE method 16S rRNA gene amplicons was established. The T1 and T2. Entic dystropept showed higher number of amplicons and Euclidean distance cluster analysis, indicate that there similarity of bacterial communities in these treatments where both vinasse as $\mathrm{KCl}$ were applied to supply $100 \%$ of source of potassium

Key-words: Inceptisol; Mollisol; PCR-DGGE, stillage, microbial communities

\section{Resumo}

O efeito da aplicação de vinhaça sobre a estrutura das comunidades bacterianas em um Entic Dystropept e um Fluventic haplustoll no Vale do Cauca, na Colômbia, foi avaliado. para atender aos requisitos de $\mathrm{K}^{+}$safra de milho doce (Zea mays L.).
O delineamento experimental foi trazado, com quatro tratamentos e cinco repetições: T1 (100\% exigência de $\left.\mathrm{K}^{+}, \mathrm{KCl}\right)$, T2 (100\% de exigência de $\mathrm{K}+$ com vinhaça ), T3 (50\% exigência de $\mathrm{K}+\mathrm{KCl}$ + $50 \%$ com vinhaça) e T4 (25\% exigência de $K^{+}$ $\mathrm{KCl}+75 \%$ com vinhaça). Foi estabelecida a relação entre a estrutura da comunidade microbiana e aplicação de vinhaça por amplicons do gene16S rRNA a través deo metodo PCR-DGGE. Os tratamentos T1 e T2 do Entic dystropept apresentaram maior número de amplicons e a análise de agrupamento de distancia euclidiana indicou similaridade da comunidade bacteriana nestes tratamentos, onde tanto a vinhaça como $\mathrm{KCl}$ foram aplicados para suprir $100 \%$ da fonte de potássio.

Palavras-chave: Inceptisol; Mollisol; PCR-DGGE, a vinhaça, comunidades microbianas

\section{Introduccion}

La vinaza es el principal residuo de la industria sucroenergetica. La relación entre producción de etanol/vinaza es aproximadamente 3:1. De acuerdo a un reporte del Grupo de Investigación en Eficiencia Energetica y Energias Alternativas (GEAL), durante el 2011 los ingenios azucareros del valle geográfico del río Cauca produjeron 351 millones de litros de bioetanol, generando alrededor de 877.5 millones de litros de vinaza, los investigadores argumentan que este volumen va en aumento de acuerdo a la política nacional de oxigenación de la gasolina. La vinaza presenta $\mathrm{pH}$ bajo, altos valores de $\mathrm{DQO}$ y $\mathrm{DBO}_{5}$, gran contenido de sólidos en suspensión, entre otros, por ello se considera como un residuo líquido que impacta negativamente el ambiente. (Bermúdez, Hoyos \& Rodriguez, 2000; Larrahondo, 2009; y Korndorfer, 2009). La resolución 0100-. Nº630 0081 de 2012, en la cual se reglamenta el uso, manejo, aplicación y almacenamiento de las vinazas, y de los productos que de ella se deriven, en el área de jurisdicción de la corporación Autónoma Regional del Valle del Cauca-CVC, indica que para tal fin es necesario establecer directrices, metodologías, criterios y procedimientos para el monitoreo y seguimiento de actividades relacionadas con estas sustancias con el fin de controlar alteraciones en los recursos naturales, agua, aire y suelo. En relación al suelo, solamente se plantean análisis antes de aplicar los subproductos de vinaza y no posterior a la aplicación que es realmente donde se tiene información del impacto positivo o negativo de esta sustancia. Los análisis previos a la aplicación son bien específicos para la caracterización tanto física como química, en el primer caso son: textura, densidad aparente, macro, meso, microporosidad y porosidad total. Los análisis químicos: $\mathrm{pH}$, materia orgánica, cationes de calcio, magnesio, sodio, potasio, capacidad intercambio catiónico; y para la salinidad especial, conductividad eléctrica, cationes solubles de calcio, magnesio, sodio, potasio, aniones: sulfatos, cloruros, carbonatos, bicarbonatos y metales pesados. Respecto a análisis biológico solo indica que se establecerá una línea base microbiológica sin especificar qué tipo de análisis contempla en relación a la caracterización siendo que ésta puede tener diferentes connotaciones incluyendo conteo, diversidad, actividad metabólica 
o estructura de sus comunidades. Según Korndörfer et al. (2004) por su alta carga de materia orgánica, la aplicación de vinaza genera cambios temporales en la población de microorganismos del suelo, tal como fue reportado por Neves et al. (1983) a través de evaluación in vitro donde se observó aumentos substanciales aunque pasajeros en poblaciones de hongos y bacterias, permaneciendo inhibida la población de actinomicetos. Resultados obtenidos en suelos del Valle del Cauca indican que la reducción del espacio poroso en el suelo (densidad aparente $>1.4 \mathrm{~g} \mathrm{~cm}^{-3}$ ) por efecto de la vinaza influye negativamente la actividad de las deshidrogenasas en el tiempo (Narváez et al., 2010); estas enzimas actúan en la degradación de materia orgánica y son importantes indicadoras del metabolismo oxidativo y de la actividad microbiana que ocurre en los suelos (Quilchano \& Marañón, 2002). Entre los métodos actuales para estudios ambientales se encuentran los moleculares contribuyendo ampliamente en la descripción microbiana a nivel genético, basado en la utilización de ácidos nucleicos tanto ADN como ARN extraído de muestras ambientales, seguido de amplificación del gen de interés por PCR y análisis de amplicones por diversas técnicas como biblioteca de clones, secuenciación, microarreglos, qPCR (real time) y DGGE (fingerprinting) entre otras(HE et al., 2007; Cárdenas \& Tiedje, 2008. Gonçalves, 2010). La asociación de las técnicas
PCR (Reacción de polimerasa en cadena) y DGGE (Electroforesis en Gel de Gradiente Desnaturalizante) posibilita amplificar y seleccionar fragmentos de DNA metagenómico microbiano presente en diversos sistemas ambientales. El DNA amplificado es separado de acuerdo a las constituciones de GC (guanina- citosina) de diversos fragmentos, construyendo un perfil de bandas que representan el fingerpinting de la comunidad microbiana, Cambios en la estructura de estas comunidades son reflejadas en el perfil de bandas obtenidas a través de DGGE (Costa, 2010). El objetivo de este estudio fue evaluar el efecto de aplicación de vinaza en la estructura de comunidades bacterianas en dos órdenes de suelos del Valle del Cauca, Colombia.

\section{Materiales y métodos}

El trabajo tuvo lugar en casa de vegetación de la Universidad Nacional de Colombia sede Palmira, Valle del Cauca (N 03 30' 45.6” y W 76 18' 29.91", 1050 m.s.n.m., $23^{\circ} \mathrm{C}$ y $70 \%$ de humedad relativa) con dos suelos de bajo contenido de potasio (Tabla 1). Las variables físicas evaluadas fueron densidad aparente, textura, estabilidad de agregados y porosidad total. La vinaza se obtuvo del Ingenio Providencia (Tabla 2).

Tabla 1. Propiedades químicas de los suelos Entic dystropept (A) y Fluventic haplustoll (B)

\begin{tabular}{|c|c|c|c|c|c|c|c|c|c|c|c|c|c|}
\hline & $\begin{array}{l}\mathrm{pH} \\
1: 1\end{array}$ & $\begin{array}{c}\text { M.O } \\
\%\end{array}$ & $\mathrm{Ca}$ & $\mathrm{Mg}$ & $\begin{array}{c}\mathrm{K} \\
\mathrm{Cmol}^{+} \mathrm{kg}^{-1}\end{array}$ & $\mathrm{Na}$ & CIC & $\mathbf{P}$ & $\mathrm{Cu}$ & $\mathbf{Z n}$ & Mn & Fe & B \\
\hline A & 5.50 & 8.10 & 6.89 & 2.63 & 0.21 & 0.18 & 14.52 & 51.00 & 2.40 & 11.00 & 57.21 & 263.00 & 0.35 \\
\hline B & 7.64 & 3.84 & 8.74 & 3.54 & 0.20 & 0.17 & 11.76 & 34.90 & 16.00 & 3.36 & 44.13 & 96.75 & 0.31 \\
\hline
\end{tabular}

Tabla 2. Composición química de vinaza del $25 \%$

\begin{tabular}{cc}
\hline Elemento & $\begin{array}{c}\text { Contenido } \\
\mathbf{k g m}^{3}\end{array}$ \\
\cline { 3 - 3 } & 0.007 \\
$\mathrm{P}_{2} \mathrm{O}_{5}$ & 0.020 \\
$\mathrm{~K}_{2} \mathrm{O}$ & 33.91 \\
$\mathrm{CaO}$ & 1.73 \\
$\mathrm{MgO}$ & 3.48 \\
$\mathrm{SO}_{4}$ & 0.031 \\
$\mathrm{Na}$ & 2.236 \\
\hline
\end{tabular}


En el experimento se utilizó un diseño completamente al azar con cuatro tratamientos generados a partir de la provisión de los requerimientos nutricionales de $\mathrm{K}^{+}$del maíz dulce (Zea mayz), con dos fuentes ( $\mathrm{KCl}$ y vinaza) y los demás requerimientos nutricionales del cultivo para una cosecha de tres a cuatro toneladas por hectárea.

Tabla 3 Mezclas de potasio aplicado antes (50\%) y después de floración (50\%) del maíz dulce

\begin{tabular}{ll}
\hline & \multicolumn{1}{c}{ Mezclas de potasio } \\
\hline T1 & $100 \% \mathrm{KCl}$ \\
T2 & $100 \%$ vinaza \\
T3 & $50 \%$ vinaza $+50 \% \mathrm{KCl}$ \\
T4 & $75 \%$ vinaza $+25 \% \mathrm{KCl}$ \\
\hline
\end{tabular}

\section{Extracción de ADN total del suelo}

Fue utilizado un protocolo de extracción de ADN total del suelo para estudio de diversidad microbiana adaptado por Lambais et al. (2005). El procedimiento fue el siguiente: En $0.5 \mathrm{~g}$. de suelo colocados en tubos de $2 \mathrm{~mL}$ con tapa rosca, fueron adicionados $1,25 \mathrm{~mL}$ de $\mathrm{Na}_{2} \mathrm{PO}_{4}$ (1 $\mathrm{mM}-\mathrm{pH} 7,0)+$ SDS $1 \%$ posteriormente 0,1 $\mathrm{g}$ de PVP(polivinilpirrolidona), se incubó a $30^{\circ} \mathrm{C}$ por 30 minutos, agitando cada 5 minutos, luego se centrifugó a $12000 \mathrm{~g}$ por 15 minutos a temperatura ambiente. El sobrenadante $(500 \mu \mathrm{L})$ fue transferido para un tubo 1,5 (Eppendorf), se adicionaron $50 \mu \mathrm{L}$ de acetato de potasio (Kac) $5 \mathrm{M}$, invirtiendo 10 veces, se incubó en hielo por 10 minutos. Se centrifugó a $12000 \mathrm{~g}$ por 5 minutos a temperatura ambiente, luego fue transferido el sobrenadante a un tubo 1,5(Eppendorf) y se adicionó un $\mathrm{mL}$ de etanol absolutamente helado, se mezcló por inversión 10 veces y se centrifugó por 15 minutos a $4^{\circ} \mathrm{C}$. Se lavó el pélete con 500 $\mu \mathrm{L}$ de etanol $70 \%$ y se centrifugó por 5 minutos a $4^{\circ} \mathrm{C}$. Posteriormente el pelete fue sacado a $37^{\circ} \mathrm{C}$ por 20 minutos y se resuspendió en $50 \mu \mathrm{L}$ de agua milliQ autoclavada. La cantidad y calidad aproximada de ADN fue confirmada en gel de agarosa al $1 \%$.

\section{Análisis de comunidades microbianas por PCR- DGGE}

Los amplicones del gen rRNA 16S fueron separados por electroforesis en gel de poliacrilamida con gradiente desnaturalizante (DGGE). EI DGGE consiste enlaseparación de fragmentos de ADN del mismo tamaño en un gel de poliacrilamida conteniendo gradiente desnaturalizante (formamida y urea) (ØVREAS et al., 1997). Las variaciones en la migración de los fragmentos de nucleótidos enel gel son referentes a las diferencias enlaconcentración de $\mathrm{G}+\mathrm{C}$. Los geles de acrilamina: bisacrilamida (37,5 : 1;m:m) $8 \%$, fueron separados con gradiente desnaturalizante variando de 15 a $55 \%$, utilizando dos soluciones: solución desnaturalizante $100 \%$, conteniendo $40 \%$ ( $\mathrm{v} / \mathrm{v})$ formamida y $7 \mathrm{M}$ urea, y solución desnaturalizante $0 \%$, sin urea y formamida (ØVREAS et al., 1997). La electroforesis fue realizada a $60^{\circ} \mathrm{C}$ e $200 \mathrm{~V}$ constantes por 4 horas, en un sistema de electroforesis vertical DCo de (BioRad Laboratories, Rio de Janeiro, BR), utilizando solución tampón TAE 0,5X (20 mM Tris-acetato, 0,5 mM EDTA, pH 8,0). Después de la electroforesis, el gel fue fijado en una solución $10 \%$ de ácido acético glacial por 15minutos. En seguida, el gel fue lavado tres veces con agua destilada, inmerso ensolución de metanol $50 \%$ por 15 minutos, lavado tres veces con agua destilada e inmerso en solución de 
VISTRA-Green I (1:10000; v/v) (GE Healthcare, São Paulo, BR) por 30 minutos. Después de la coloración, el gel fue lavado tres veces en agua destilada y analizado por densitometría, utilizándose un densiometro laser Fluorlmager (GEHealthcare, São Paulo, BR) y el programa Fragment Analysis (GE Healthcare, São Paulo, BR). Los geles fueron analizados utilizando el programa Diversity Database (Bio-RadLaboratories, Rio de Janeiro, BR).

Para determinación de riqueza de los amplicones de las muestras, se realizó un análisis de similaridad entre las estructuras de las comunidades bacterianas a través de concordancia simple ("simplematching"), usándose el algoritmo de Ward y la distancia euclidiana como medida, a través del programa Systat 12, con base en datos binarios para presencia ó ausencia $(1 \circ 0)$ de las bandasdetectadas después del DGGE.

\section{Resultados}

Los suelos estudiados difieren sustancialmente en contenidos de materia orgánica con mayor porcentaje en el Entic dystropept (Tabla 1), el pH de este suelo es ligeramente ácido y el Fluventic haplustoll corresponde a un suelo neutro, con ligera tendencia a la basicidad. La densidad aparente del Entic dystropept presentó disminución significativa al finalizar el ensayo con respecto a los valores iníciales, por su parte en el Fluventic haplustoll se incrementó con valores superiores a $1.4 \mathrm{~g} \mathrm{~cm}^{3}$, con consecuente disminución de la porosidad (Narváez et al., 2010).

La estructura de comunidades bacterianas de cada suelo se observa en las bandas generadas por el DGGE (Figura 1), cada banda en el gel puede representar más de un genotipo bacteriano, por esta razón no es posible establecer una relación directa entre la cantidad de bandas detectadas por DGGE y el número de especies presentes (Lambais et al., 2005), no obstante, es posible tener un panorama general de respuesta microbiana ante un agente externo. La Figura 2 muestra el número de amplicones de cada tratamiento, donde el mayor número fue para $\mathrm{T} 1$ y $\mathrm{T} 2, \mathrm{KCl} 100 \%$ y vinaza $100 \%$, respectivamente.

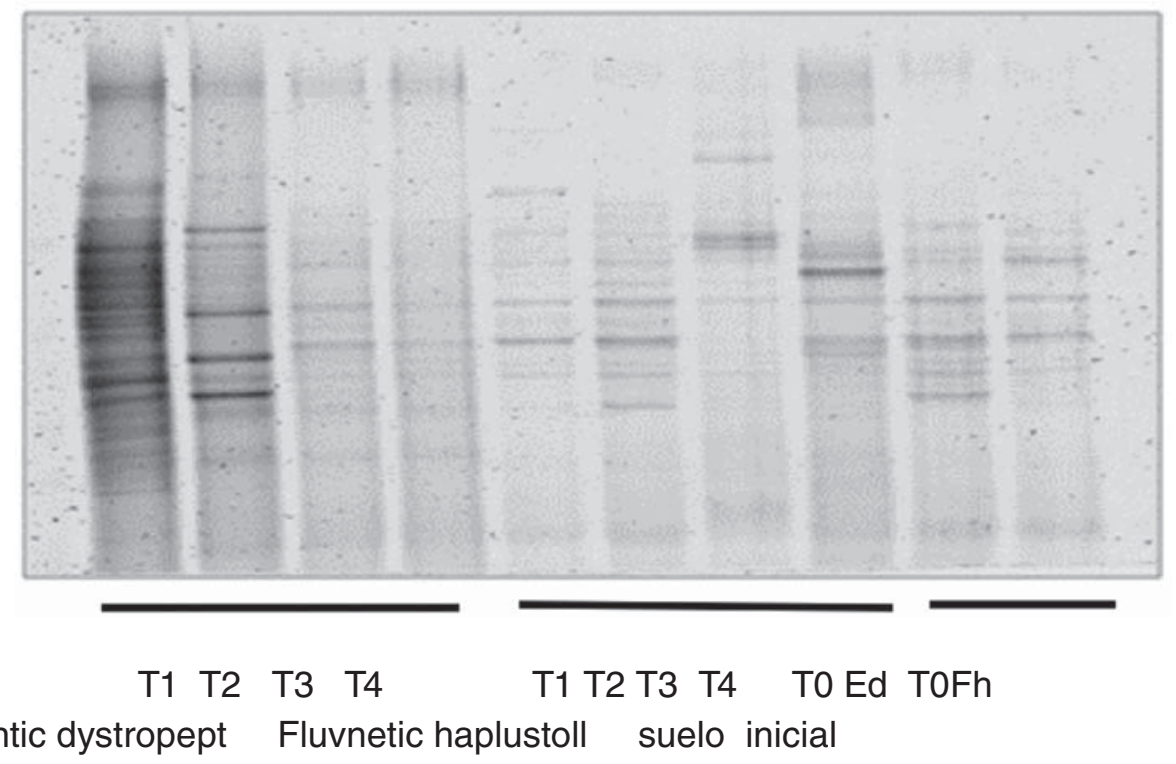

Figura 1. DGGE de amplicones de rRNA $16 \mathrm{~S}$ de Bacteria en un Entic dystropept (Ed) y un Fluventic haplustoll (Fh) bajo influencia de aplicación de vinaza T1 (KCl 100\%), (T2 vinaza 100\%), (T3 KCl 50\%, vinaza 50\%), (T4 vinaza $75 \%, \mathrm{KCl} 25 \%$ ). T0 indica ausencia de vinaza en cada orden de suelo. 


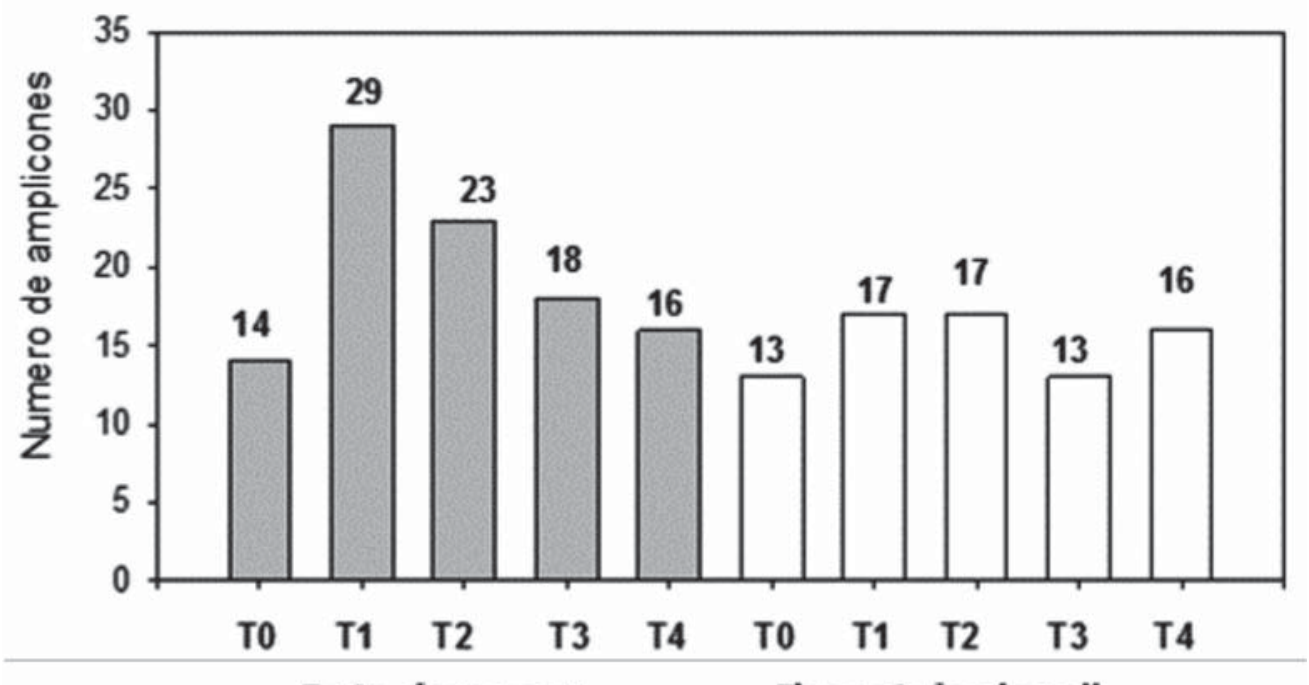

Entic dystropept

Fluventic haplustoll

Figura 2.Riqueza de amplicones de rRNA $16 \mathrm{~S}$ de bacterias por PCR- DGGE presentes en un Entic dystropept y un Fluventic haplustoll bajo influencia de aplicación de vinaza T1 (KCl 100\%), (T2 vinaza 100\%), (T3 $\mathrm{KCl} 50 \%$, vinaza $50 \%$ ), (T4 vinaza $75 \%, \mathrm{KCl} 25 \%$ ). T0 indica ausencia vinaza en cada orden de suelo.

Los resultados basados en presencia y ausencia de bandas detectadas en el gel DGGE fueron agrupados en un clúster jerárquico (Figura 3). La similaridad microbiana basada en los amplicones presentes se analizó a través de la distancia euclidiana.

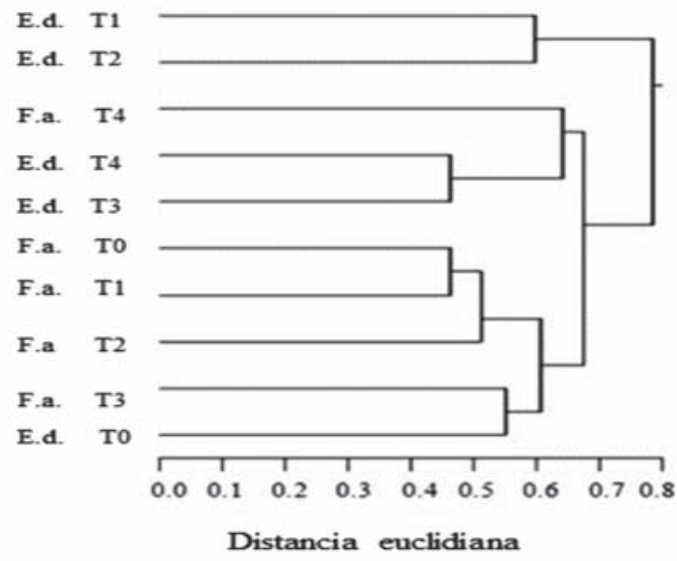

Figura 3. Agrupamiento jerárquico con base en separación de amplicones de rRNA 165 de bacteria por PCR- DGGE presentes en un Entic dystropept (Ed) y un Fluventic haplustoll (Fh) bajo influencia de aplicación de vinaza T1 (KCl 100\%), (T2 vinaza100\%), (T3 $\mathrm{KCl} 50 \%$, vinaza 50\%), (T4 vinaza 75\%, $\mathrm{KCl} 25 \%$ ). T0 indica ausencia de vinaza en cada orden de suelo.

En conjunto con el agrupamiento jerárquico se realizó un análisis multivariado NMDS (Análisis no métrico dimensional con Primer 5), seguido de un análisis de similaridad (análisis múltiple de similaridad), este análisis se realizó basado en el agrupamiento de las muestras antes y después de aplicación de vinazas y considerando las variables ambientales $\mathrm{pH}$, ma- teria orgánica y también variables microbiológicas biomasa y actividad microbiana - CO2 y cociente metabólico qCO2 (datos no presentados). Los resultados indican de modo general que los suelos fueron agrupados de forma dispersa antes de aplicación de tratamientos y de una forma más estrecha después de aplicación de los mismos (Figura 4). 


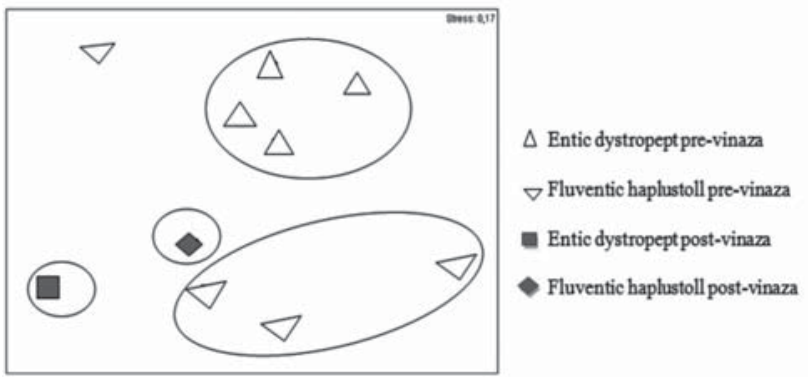

Figura 4. Análisis NMDS con base en separación de amplicones de rRNA $16 \mathrm{~S}$ de bacteria, $\mathrm{pH}$, materia orgánica, biomasa microbiana- $\mathrm{C}$, respiración mirobiana-CO2, presentes en un en un Entic dystropept y un Fluventic haplustoll antes de aplicación de vinaza (pre-vinaza) y después de aplicación(post-vinaza) (T1 KCl 100\%), (T2 vinaza 100\%), (T3 KCl 50\%, vinaza $50 \%$ ), (T4 vinaza $75 \%, \mathrm{KCl} 25 \%$ ).

\section{Discusión y conclusiones}

Los resultados obtenidos por distancia euclidiana (Figura 3) agrupan los tratamientos T1, T2 del Entic dystropept en un solo clúster indicando que no existen diferencias estadísticas entre ellos. El agrupamiento y mayor número de microorganismos bacterianos en los tratamientos mencionados indica que las mezclas no favorecieron su crecimiento, sin embargo es importante considerar el sistema de cultivo ya que en el caso de actividad microbiológica esta se encuentran estrechamente relacionada a los factores suelo-cultivo (Hernández et al., 2003), en este sentido Rosero et al., (2013) reportó en un cultivo de habichuela que la mezcla en cantidades iguales de $\mathrm{K}$ y vinaza favoreció la biomasa microbiana en diferentes suelos, en contraster esultados de la actividad de deshidrogenasa reportados por Narváez et al., (2010) en los mismos suelos del presente estudio indican en el Fluventic Haplustoll baja actividad de la enzima, argumentando posibles efectos del deterioro físico de este suelo al agregar vinaza, principalmente incremento de la densidad aparente (D.A. $>1.4 \mathrm{~g} \mathrm{~cm}^{-3}$ ) lo cual influye en la reducción del espacio poroso, creando condiciones anaerobias, que además de disminuir la actividad de la biomasa microbiana, afectan el estado metabólico y la producción de enzimas por las células (Tejada, García. Moreno \& Hernández, 2007). Estos resultados son concordantes con los reportados por Montenegro et al. (2009) donde microorganismos del suelo Fluventic haplustoll se afectaron negativamente en contenido de biomasa microbiana y cociente metabólico (qCO2), los datos de estas variables biológicas fueron consideradas en el presente estudio para ser correlacionadas con la estructura de comunidades bacterianas (Figura 4), los resultados presentan claramente agrupación dispersa de los tratamientos antes de aplicar vinaza, esta agrupación cambia a una forma compacta cuando se aplica vinaza, lo que sugiere comportamiento de respuesta microbiana a la aplicación de vinaza tanto en el Entic dystropept como en el Fluventic haplustoll, en este sentido las propiedades del suelo juegan un papel importante ya que siempre va a existir impacto de respuesta, pero en la medida en que las condiciones del suelo estén química, física y biológicamente estables la resiliencia será mayor ante efectos negativos de compuestos presentes en residuos como la vinaza que si bien puede ser benéfico para los microorganismos en algunos casos como T2 del Entic dystropept de este estudio, también puede ser muy perjudicial en suelos degradados físicamente.

Los resultados obtenidos en T1 y T2 del Entic dystropept indican que existe similaridad de comunidades bacterianas en estos tratamientos donde tanto la vinaza como $\mathrm{KCl}$ fueron aplicados para suplir el $100 \%$ de fuente de potasio

\section{Agradecimientos}

Al grupo de investigación en "Uso, manejo de suelos y aguas con énfasis en degradación de suelos" por el soporte técnico, científico y financiero de la Tesis de Maestría de la cual se derivó el artículo. Al Doctor. Nelson Virgilio Piraneque, profesor en la Universidad de Magdalena, por su apoyo tanto en la parte práctica como en el análisis de los resultados aquí presentados los cuales en su mayoría fueron procesados en el laboratorio de microbiología molecular de la Escola Superior de Agricultura Luiz de Queiroz-Universidad de Sao Paulo, coordinado por el profesor-Doctor Marcio Rodrigues Lambais. 


\section{Literatura citada}

1. Bermúdez, R., Hoyos, J \& Rodríguez, S., (2000) Evaluación de la disminución de la carga contaminante de la vinaza de destilería por ensayo anaeróbico. Revista internacional de contaminación ambiental, 16, pp. $103-107$

2. Cárdenas, E. \& Tiedie, J. M. (2008). New tools for discovering and characterizing microbial diversity. Current Opinion in Biotecnology, Amsterdam, v. 19, p. 544-549

3. Costa, C. T. R.C. da. (2010). Comunidade bacteriana, atributos do solo e fluxo de gases em solo sob cerrado e cana de açúcar, 126 p.. (Tesis de maestria) -Centro de Energia Nuclear na Agricultura. Universidade de Sao Paulo.

4. Gonçalves, B.Vinhaça da cana de açúcar: Fluxos de gases de efeito estufa e as comunidades de archea presente no sedimento do canal de distribuição (2010), 96 p. (Tesis de maestria) - Escola Superior de Agricultura Luiz de Queiroz. Universidade de São Paulo.

5. He, Z., Gemtry, T. J., Schadt, C. W., Wu, L., Liebich, J., Chong, S. C., Huang, Z., Wu, W., Gu, B., Jardine, P., Criddle, C. \& Zhou, J. (2007) Geochip: a comprehensive microarray for investigating biogeochemical, ecological and environmental process. The ISME Journal, London, v. 1, p. 67-71.

6. Hernández, W., Rojas, J., Rivero, C., Centeno, A. \& Paolini, J. (2003). Efecto de tres sistemas de labranza de un suelo cultivado con maíz (Zea maysL.) Rev. Agron. Maracay.29:171 - 18.

7. Korndorfer, G., (2009) Impacto ambiental del uso de la vinaza en la agricultura y su influencia en las características químicas y físicas del suelo. Memorias Seminario internacional de Fertilización y Nutrición de la Caña de Azúcar, Tecnicaña. Cali, Colombia, pp. 115 - 122

8. Korndofer, Nolla, A., Waldo, A. \& Lara, C. (2004) Impacto ambiental del uso de la vinaza en la agricultura y su influencia en las características químicas y físicas del suelo en: Encuentro sobre vinazas, potasio y elementos menores para una agricultura sostenible, Palmira, Colombia, 14 y 15 de mayo de 2004, Corpoica, 233 p.
9. Lambais, M., De Carvalho, J., Baretta, C. \& Campos, R. (2005). Diversidade microbiana nos solos: Definindo novos paradigmas. Tópicos Ci. Solo, 4:43-84

10. Larrahondo, J., (2009) La vinaza: Caracterización de la vinaza, usos y aprovechamientos potenciales. Memorias Seminario internacional de Fertilización y Nutrición de la Caña de Azúcar, Tecnicaña. Cali, Colombia, pp. $69-90$.

11. Montenegro, G. S., Menjivar, F. J., Bonilla, C. C. \& Madriñan, M. R. (2009). Influencia de la aplicación de vinaza en la actividad y biomasa microbiana en un Entic Dystropety un Fluventic haplustoll del Valle del Cauca Colombia. Acta Agron. 58(01):41 - 45.

12. Narváez, C. M., Sánchez de P., M. \& Menjivar, J. (2010). Efecto de la aplicación de vinazas en las propiedades físicas y la actividad de deshidrogenasas en suelos cultivados con maíz dulce (Zea maysL.) Acta Agronómica, Universidad Nacional de Colombia, vol. 59, núm. 2, 2010, pp. 211-217.

13. Neves, M., Lima, I. T. \& Dobereiner, J. (1983) Efeito da vinhaça sofre a a microflora do solo. En: Revista Brasileira de ciência do solo. $N^{\circ}$ 7. P 131-136

14. Øveras, L., Forney, L. \& Frida, L. D. (1997). Distribution of Bacterioplankton in Meromictic Lake Sælenvannet, as Determined by Denaturing Gradient Gel Electrophoresis of PCR-Amplified Gene Fragments Coding for 16S rRNA. Appl. Environ. Microbiol., 63: 3367-3373.

15. Quilchano, C. \& Marañon, T. (2002). Dehydrogenasea activity in Mediterranean forest. SoilBiol, Fertile Soils. 35:102 - 107.

16. Rosero, M., Vargas, W. \& Menjivar, J. (2013) Efectos de vinazas sobre bacterias rizosféricas y en la actividad$\mathrm{CO} 2$ y biomasa-C microbiana de un suelo Pachic Haplustoll. Acta Agronomica, Universidad Nacional de Colombia, vol 62, num 2 2013, p 165-173

17. Tejada, M.,Garcia, C., Moreno, J. \& Hernandez, M. (2007) Application of two beet vinasse forms in soil restoration: Effects on soil properties in an arid environment in southern Spain. Agric. Ecol. Environ. 119:289 - 298. 